(for example, differentiating between a muddy technical explanation and poor experimental technique). Knowing author identities also makes it easier to compare the new manuscript with the authors' previously published work, to ensure that a true advance is being reported. And knowing rather than guessing the identities of authors encourages reviewers to raise potential conflicts of interest to the editors.

Is there evidence that double-blind peer review presents a better alternative? It would do so if it generated more constructive comments in the minds of editors and authors, or if the identity of authors were truly protected, or if biases were reduced. So far, the jury is out. Although at least one study in the biomedical literature has suggested that double-blind peer review increases the quality of reviews, a larger study of seven medical journals ${ }^{2,3}$ indicated that neither authors nor editors found significant difference in the quality of comments when both referees and authors were blinded. Referees could identify at least one of the authors on about $40 \%$ of the papers, undermining the raison d'être for double-blinding. The editors at the Public Library of Science abandoned double-blind peer review because too few requested it and authors were too readily identified.

The one bright light in favour of double-blind peer review is the measured reduction in bias against authors with female first names (shown in numerous studies, such as ref. 4). This suggests that authors submitting papers to traditionally minded journals should include the given names of authors only on the final, published version.

The double-blind approach is predicated on a culture in which manuscripts-in-progress are kept secret. This is true for the most part in the life sciences. But some physical sciences, such as high-energy physics, share preprints extensively through arXiv, an online repository. Thus, double-blind peer review is at odds with another 'force for good' in the academic world: the open sharing of information. The PRC survey found that highly competitive fields (such as neuroscience) or those with larger commercial or applied interests (such as materials science and chemical engineering) were the most enthusiastic about double-blinding, whereas fields with more of a tradition for openness (astronomy and mathematics) were decidedly less supportive.

Where does this leave journals? Editors have the responsibility to provide a neutral bridge between referees and authors and so may help to better shield authors from bias. Easily said! The evidence of the PRC survey suggests little faith in that impartiality, but editors - certainly at Nature and its related journals - take that responsibility seriously.

Nature's policies over the years have generally moved towards greater transparency. Coupling that with the lack of evidence that double-anonymity is beneficial makes this journal resistant to adopting it as the default refereeing policy any time soon. But many of our readers are referees as well as authors. We welcome their views on author anonymity from both vantage points. To that end, this Editorial will be posted for comment at http://blogs.nature.com/peer-topeer/2008/02/working_doubleblind.html.

1. Publishing Research Consortium Peer Review in Scholarly Journals (Mark Ware Consulting,

Bristol, 2008); available at http://www.publishingresearch.net/PeerReview.htm

2. Justice, A. C. et al. J. Am. Med. Assoc. 280, 240-242 (1998).

3. Cho, M. K. et al. J. Am. Med. Assoc. 280, 243-245 (1998).

4. Budden, A. E. et al. Trends Ecol. Evol. 23, 4-6 (2008).

\section{Don't ban labels}

\section{Providing context for sensitive declarations is the job of industry and government.}

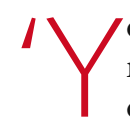

ou are what you eat' notwithstanding, it is only recently that most consumers have become interested in the technical details of their food's composition, production and transport. With obesity and climate change now major concerns, and 'localvore' and 'food miles' entering the lexicon, shoppers are clamouring for information. And many food companies are happy to supply it, resulting in a dizzying array of multicoloured labels and claims.

But not everyone is happy. A proposed law in Indiana is the latest attempt in the United States to ban milk labels proclaiming that the cows from whence the milk came were not treated with recombinant bovine growth hormone ( $\mathrm{rBGH}$, also called recombinant bovine somatotropin or rbST). This hormone is produced by engineered bacteria, is virtually identical to the cow's own and can increase milk production by $10-15 \%$.

There are two bad arguments for banning such labels. The first - that it is impossible to determine from the milk whether the cow was injected with $\mathrm{rBGH}$ - is the reason cited in the bill language. The second - that a proliferation of 'no rBGH' labels will train consumers to distrust the product - is the real motivation.

The first argument can be disposed of easily: it is already illegal to make false claims about a product. The second argument may seem more convincing. There is no firm scientific evidence that injecting cows with $\mathrm{rBGH}$ affects human health in any way, but prevalent labelling touting the absence of $\mathrm{rBGH}$ would suggest to consumers that there are some differences. The mandating of an additional phrase such as that agreed last month in Pennsylvania - "No significant difference has been shown between milk derived from rbST-treated and non-rbST-treated cows" - ameliorates this problem.

The hormone injections may not affect the milk, but they are rough on the cows: producing all that milk causes problems such as udder infections and lameness. For some consumers, this may be a sufficient reason to avoid milk from dairies using the injections. Indeed, it was, in part, animal welfare that led Canada and the European Union to ban them.

There are good reasons not to ban accurate labels. More information means that consumers can be more discerning, and not just about their own health. They can vote with their purchases for farming practices they prefer. And if a company wants to use a technology with a bad reputation, it is the firm's responsibility to educate the consumer about why it is beneficial. If consumers choose irrationally to reject it, that is their prerogative. Capitalism thrives on the irrationality of consumers, from their noted fear of smelling bad, to their preference for redness in apples, farmed salmon and fast-food signage.

Indeed, if consumers were suddenly to become rational, an economic cataclysm would result, as households in all the rich nations would cut their consumption to only what they really needed. Such a crash would no doubt make the current economic doldrums look like the mildest hiccup. 